if "direct" karyotype analysis of rapidly dividing trophoblast nuclei is combined with conventional culture of slowly dividing cells from the mesenchymal cores of the chorionic villi. ${ }^{12}$

Even before publication of the Medical Research Council trial, members of the prenatal study group (sponsored by the Royal College of Obstetricians and Gynaecologists and the Department of Health) had concluded that chorionic villus sampling has the greatest relative value for women with a higher risk of having genetically abnormal babies, such as those at high risk of a single gene defect or unbalanced translocation of chromosomes. There are several reasons for this. Firstly, the risk of miscarriage (and perhaps other adverse outcomes) is higher with chorionic villus sampling than with amniocentesis: these fixed risks remain the same while the benefits of early diagnosis become proportionately more important as genetic risk rises - a point that has been proved formally using decision theory. ${ }^{13}$ Secondly, most invasive prenatal diagnostic procedures are performed in women who are at low risk of trisomy, and the cost of chorionic villus sampling for cytogenetic indications is double that for amniocentesis because both direct preparations and culture are needed. ${ }^{1+}$ And, lastly, ambiguous cytogenetic results requiring subsequent elucidation are four times more common with chorionic villi than they are with cultured amniotic fluid. Chorionic villi, on the other hand, provide large amounts of metabolically active cytoplasm and DNA for enzyme and gene probe diagnosis in single gene defects with high recurrent risks.

"Real time" ultrasonography allows amniocentesis to be performed at 12 weeks' gestation or less. Could this provide the best of both worlds? Amniocentesis may cause pulmonary hypoplasia, ${ }^{15}$ however, and animal experiments suggest that this risk is inversely proportional to gestational age ${ }^{16}$ Several randomised trials are looking for this and other adverse effects of early amniocentesis. These trials are likely to detect only large increases in rare side effects ${ }^{17}$; hence the possibility of iatrogenic harm below the threshold of statistical detection must be included in counselling, especially when couples at low risk request prenatal diagnosis. This is a strong argument for using other markers (such as biochemical variables and ultrasonic appearances) rather than age alone to determine the risk of aneuploidy.

Those of us who wish to avoid central licensing of all surgical procedures ${ }^{18}$ will be able to resist it more persuasively if we subject new techniques to voluntary scrutiny by randomised controlled trials. These two large studies that have compared different prenatal diagnostic procedures are good examples of the voluntary assessment of invasive procedures.

Professor of Obstetrics and Gynaecology, St James's University Hospital,

Leeds LS9 7TF

1 Canadian Collaborative CVS-Amniocentesis Clinical Trial Group. Multicentre randomised clinical trial of chorionic villus sampling and amniocentesis. Lancet 1989;i:1-6.

2 MRC Working Party on the Evaluation of Chorionic Villus Sampling. Medical Research Council European trial of chorionic villus sampling. Lancet 1991;337:1491-9.

3 Brambati B, Lanzani A, Tului $L$. Transabdominal versus transcervical chorionic villus sampling: efficiency and risk evaluation of 2,411 cases. Am f Med Genet 1990;35:160-4.

4 Firth HV, Boyd PA, Chamberlain P, Mackenzie IZ, Lindenbaum RH, Huson SM. Severe limb abnormalities after chorionic villus sampling at 56-66 days' gestation. Lancet 1991;337:762-3. Mastroiacovo P, Cavalcanti DP. Limb-reduction defects and chorionic villus sampling. Lancet 1991;337:1091.

6 Hsieh F, Chen D, Tseng L, Lee C, Ko T, Chuang S, et al. Limb-reduction defects and chorionic villus sampling. Lancet 1991;337:1091-2.

Miny P, Holzgreve W, Horst J, Lenz W. Limb abnormalities and chorionic villus sampling. Lancet 1991;337:1423-4.

8 Mahoney MJ, for the USNICHD Collaborative CVS Study Group. Limb abnormalities and chorionic villus sampling. Lancet 1991;333:1422-3.

9 Jackson LG, Wapner RJ, Brambati B. Limb abnormalities and chorionic villus sampling. Lancet 1991;337:1423.

10 Froster-Iskenius UG, Baird PA. Limb reduction defects in over one million consecutive livebirths. Teratology 1989;39:127-35

11 Lilford RJ. Invasive diagnostic procedures. In: Prenatal diagnosis and prognosis. London: Butterworths, 1990:208-25.

12 Gosden CM. Fetal karyotyping using chorionic villus samples. In: Drife JO, Donnai D, eds. Antenatal diagnosis of fetal abnormalities. Berlin: Springer Verlag, 1991:153-67.

13 Lilford R. Trade-off between gestational age and miscarriage risk of prenatal testing: does it vary according to genetic risk? Lancet 1990;336:1303-5.

14 Lilford RJ, Irving H, Gupta JK, O'Donovan P, Linton G. Transabdominal chorionic villus biopsy versus amniocentesis for diagnosis of aneuploidy: safety is not enough. In: Chapman $M$, Grudzinskas G, Chard T, Maxwell D, eds. The embryo-normal and abnormal development and growth. Berlin: Springer Verlag, 1990:91-100.

15 Tabor A, Madsen M, Obel EB, Philip J, Bang J, Noorgaard-Pederson B. Randomised controlled trial of genetic amniocentesis in 4,606 low-risk women. Lancet 1986;i:1287-93.

16 Heslop AF, Fairweather DVI, Blackwill RJ, Howard S. The effect of amniocentesis and drainage of amniotic fluid on lung development in maca fascicularis during fetal and postnatal life. $\mathrm{Br} \mathcal{F}$ Obstet Gynaecol 1984;91:835-42.

17 Orrell RW, Lilford RJ. Chorionic villus sampling and rare side effects. Will a randomised trial detect them? Int 7 Gynecol Obstet 1990;32:29-34.

18 Guiding the knife. The Economist 1991 May 4-10:11.

\title{
The right to know
}

\section{Patients' records should be understandable by patients, too}

Patients have had access to their computerised medical records since 1984 and from next month will have access to their written records as well. ${ }^{1}$ Is it time to go even further down this path?

Many doctors find the prospect of patients reading their records disquieting. Recent reviews, however, have emphasised the benefits of giving patients greater access, ${ }^{23}$ echoing the advice of 20 years ago. Analysing the consequences of American legislation to give patients access to their entire medical record, Shenkin and Warner concluded that open access would improve patients' adherence to treatment, improve the efficiency of the service, and strengthen the role of the profession. ${ }^{4}$

Concern that sharing information with patients may cause sustained psychological distress is probably unfounded. Showing them incomprehensible jargon or pejorative comments will understandably confuse or distress, but this is a powerful argument for changing the way records are written, not keeping them secret. Danish patients have a statutory right to see their entire hospital record; in one large teaching hospital only $0.4 \%$ of patients exercised this right during one year. Both doctors and patients regarded access positively, and no ill effects were observed. ${ }^{5}$

Psychiatric patients may respond less favourably than other patients shown their records. Although a study in general practice $^{6}$ and another of psychiatric outpatients reported in this week's journal ( $\mathrm{p} 967)^{7}$ suggest that this might be true, another of forensic patients given access to the daily record made by all disciplines thought that they were "better able to discuss their problems with staff, better able to put forward their own views and considered that access enabled them to correct errors." "It has been argued that the short term distress suffered by some psychiatric patients may in the longer term be therapeutic. ${ }^{9}$

Other arguments used against giving patients greater access to their records are that modifying records to make them comprehensible and palatable to patients would require too much effort ${ }^{10}$ and that doctors might restrict their notes to the 
bare minimum, making them useless to their patients and other doctors alike, or even keep a second set of records under the consulting room table.

Ethical arguments, however, support greater access. Koenigsberger regards the basic question as being not whether access can be harmful but whether patients have a right to know everything about their state of health.$^{11}$ Hochuli has argued that most medical interventions carry a risk of adverse effects to a few patients and that this risk is not a valid argument against greater access. ${ }^{12}$

Should doctors just acquiesce to the new legislation and leave it at that? If they do so they are missing an important opportunity to improve communication between doctors and patients and much else besides. If the potential benefits of greater access are as extensive as the research suggests then a low rate of requests for access should be a cause for concern rather than relief.

To facilitate access new ways of writing records for patients will need to be evolved. New ways of keeping records have been studied and their effects on patients found to be positive. Summary records held by patients have proved successful in obstetrics, ${ }^{13}$ diabetic care,${ }^{14}$ and general medicine. ${ }^{15}$ In psychiatry, where particular concern has been expressed about the potential damage to patients, such records have been used successfully, including among the homeless mentally ill. ${ }^{16}$

The argument against giving patients greater access to their records has been lost; the challenge now is to get doctors skilled in writing records that their patients (as well as their medical colleagues) will find useful. The benefits of such an approach should outweigh the effort required. The change in legislation giving patients greater rights of access should therefore be viewed as a window of opportunity rather than intrusive meddling.

Research Psychiatrist,

PAUL MCLAREN

United Medical and Dental School,

Guy's Hospital,

London SE1 9RT

1 Warden J. Patients to see medical records. BMF 1991;303:538

2 Kirby BJ. Patient access to medical records. $\mathcal{F} R$ Coll Physicians Lond 1991;25:240-2.

Gillhooly MLM, McGhee SM. Medical records: practicalities and principles of patient possession. 7. Med Ethics 1991;17:138-43.

4 Shenkin BN, Warner DC. Giving the patient his medical record: a proposal to improve the system. N Engl f Med 1973:289:688-90.

Andersen $T$, Jorgensen G. Danish experiences of statutory right of patients to access hospital records. Lancet $1988 ;$ ii: 1428

6 Baldry M, Cheal C, Fisher B, Gillett M, Huet V. Giving patients their own records in general practice: experience of patients and staff. BMF 1986:292:596-7.

7 Bernadt $M$, Gunning L, Quenstedt $M$. Patients' access to their own psychiatric records. BMF 1991;303:967.

8 Parrot J, Strathdee G, Brown P. Patient access to psychiatric records: the patient's view. $\mathcal{F} R$ So Med 1988;81:520-2.

9 Stoller RJ. Patients' responses to their own case reports. F Am Psychoanal Assoc 1988;36:371-91. 10 Short D. Some consequences of granting patients access to consultants' records. Lancet $1986 ; 1: 1316$

11 Koenigsberger CW. Access to medical records. Lancet 1986; ; 1445 .

2 Hochuli VK. Access to medical records. Lancet 1986;i:1445.

13 Lovell A, Zander LL, James CE, Foot S, Swan AV, Reynolds A. The St Thomas' Hospital maternity case notes study: a randomised controlled trial to assess the effects of giving expectant mothers their own maternity case notes. Paediatr Perinat Epidemiol 1987;1:57-66.

14 Jones RB, Hedley AJ, Allison SP, Tattersall RB. Censoring of patient-held records by doctors. Journal of the Royal College of General Practitioners 1988;38:117-8.

15 Ellis DA, Hopkins JM, Leitch AG, Crofton J. "Doctors' orders:" controlled trial of supplementary written information for patients. BM7 1979:i:456.

16 Reuler JB, Balazs JR. Portable medical record for the homeless mentally ill. BMF 1991;303:446

\title{
Ion channels: this year's Nobel prize in physiology or medicine
}

\author{
Opening channels of communication
}

A revolution on the scale wrought by Erwin Neher and Bert Sakmann is rare indeed so it is entirely appropriate that they should have received this year's Nobel prize in physiology or medicine for their work on cellular communications that involve electrical signals. Their basic idea is simple.

The lipid cell membrane is impermeable to ions, so ionic currents are carried through the membrane by specialised protein molecules - ion channels - that span the membrane. On sensing an appropriate electrical or chemical stimulus ion channels change shape, producing a pore in the membrane through which ions can flow. Such ion channels are important not only in excitable tissues (for example, for the propagation of nervous impulses and for synaptic transmission) but also for just about every other cell type too-from secretory cells to lymphocytes.

The idea that such ion channels must exist evolved during the 1950s, mainly from the work of Alan Hodgkin and Andrew Huxley in Cambridge on the nerve impulse and that of Bernard Katz at University College London on synaptic transmission from motor nerve to muscle. By the early 1970 s there was enough indirect evidence about the channels to guess that a current of a few picoamps must flow through each channel. The noisiness of the recording methods, however, was about 100 times too large to allow such tiny currents to be observed directly. The neuroscientific world was, therefore, stunned when Neher and Sakmann succeeded in observing the currents through single ion channels by means of a new method, the patch clamp technique. ${ }^{1}$

This method allows one to watch, as it is happening, the activity of an individual molecule, something that most chemists and physicists cannot do. The method entails touching a micropipette (tip diameter about $1 \mu \mathrm{m}$ ) against the external surface of the cell membrane in such a way that a high resistance seal is formed between the glass and the membrane, thus isolating a very small area of membrane. When an ion channel opens in this patch of membrane the current flows up the micropipette and can be measured with a sensitive ammeter. ${ }^{2}$

At the Max Planck Institute for Biophysical Chemistry in Göttingen, Erwin Neher (trained as a physicist) and Bert Sakmann (trained in medicine, and now working in Heidelberg) not only developed the method but also pioneered most of its important applications. Initially they used the method to investigate the mechanisms of the nicotinic acetylcholine receptors, ${ }^{3-6}$ work that also involved new theoretical approaches to deal with the random probabilistic behaviour of single molecules. ${ }^{7}$ Neher developed a variant of the method that allowed the fusion of secretory vesicles with the cell membrane in mast cells to be observed directly $^{8}$ and has gone on to make enormous contributions to problems of neurosecretion. ${ }^{9}$ Sakmann has a longstanding interest in the development of synapses ${ }^{10}$ and has done pioneering studies, in collaboration with molecular biologists, on the relation between the protein structure of ion channels and their function. ${ }^{11} 12$ More recently he has started to define the nature of synaptic transmission in the brain with the sort of precision, unimaginable without the patch clamp, that was achieved 20 years ago in the peripheral nervous system. ${ }^{13}$ 